\title{
From Computer Science to the Informational Worldview. Philosophical Interpretations of Some Computer Science Concepts
}

\author{
Paweł Stacewicz*
}

\begin{abstract}
In this article I defend the thesis that modern computer science has a significant philosophical potential, which is expressed in a form of worldview, called here informational worldview (IVW). It includes such theses like: a) each being contains a certain informational content (which may be revealed by computer science concepts, such as code or algorithm), b) the mind is an information processing system (which should be modeled by means of data processing systems), c) cognition is a type of computation. These (pre)philosophical theses are accepted in many sciences (e.g. in cognitive science), and this is both an expression and strengthening of the IWV. After a general discussion of the relations between philosophy, particular sciences and the worldview, and then the presentation of the basic assumptions and theses of the IWV, I analyze a certain specification of thesis b) expressed in the statement that "the mind is the Turing machine". I distinguish three concepts of mind (static, variable and minimal) and explain how each of them is connected with the concept of the Turing machine.
\end{abstract}

Keywords: philosophy, informational worldview, information, computation, informatism, mind, Turing machine.

\section{Introduction}

This article presents computer science as a domain important both in terms of worldview and philosophically. The central concept of the work, i.e. informational worldview, is a kind of conceptual "interface" between information sciences (in particular: computer science) and various branches of philosophy (in particular: philosophy of mind) ${ }^{1}$.

\footnotetext{
* Faculty of Administration and Social Sciences, Warsaw University of Technology (p.stacewicz@ans.pw.edu.pl)

${ }^{1}$ The notion of the informational worldview discussed in this article was introduced for the first time in [18], and then it was developed in [22] and [23]. Different threads of the informational worldview have been discussed since 2012 in the academic blog "Café Aleph" [5]. Similar conceptions are presented in [7] and [13].
} 
Initially speaking, it means a certain type of prephilosophical views that are scientifically grounded (mainly by computer science) and based on the assumption that computer science concepts such as data, code, algorithm or computability play a very important role in describing the world and human-world relations. For example, within this view of the world, the human mind - something that enables the "activation" of the relationship between man and the world - is described as an information processing system, modeled partially by means of appropriate data processing systems.

The presented work consists of three parts. In the first part, which includes chapters 2 and 3, I discuss in general terms the relationship between philosophy, the worldview and the specific sciences, making them more concrete in relation to computer science. In the next chapter I clarify the idea of the informational worldview, placing it in a wider conceptual structure (including informational pre-awareness, informational awareness and informational philosophy), and then I explain computer science concepts that are key to this idea. In the last chapter I analyse in detail one of the theses of informational worldview - a thesis which is very close to philosophy and is summarized in the slogan that "the human mind is a Turing machine".

\section{Particular sciences, philosophy and worldview}

2.1. In the vast majority of classifications of sciences, philosophy differs from particular sciences $^{2}$, and is presented as the most general discipline. This distinction is justified by the fact that the key philosophical concepts include: being, cognition, time, space, matter or spirit; i.e., the most general ones, referring to the broadest possible classes of objects and being the basis for the most general theses. For example, the term "being" means all possible things, processes, properties, or relationships; and the claims of the theory of being, also called ontology, are to apply to all beings. A similar degree of generality is characteristic of the theory of knowledge (or epistemology), which examines the nature of all knowledge and all methods of obtaining and justifying it ${ }^{3}$. (See [1], [26]).

The general nature of philosophical concepts gives them a character of scientific universality. This means that they occur in various (sometimes even: all) sciences, determining the majority of research undertaken within them. For example: the above

\footnotetext{
${ }^{2}$ In this text, by particular sciences I will mean sciences with a clearly defined subject and method, exploring certain distinguished parts of reality (such as physics, chemistry, computer science, sociology, or algebra).

${ }^{3}$ In order to give a picture of the general character of philosophical theses, it is worth to mention some of them, together with an indication of the area of philosophy to which they belong.

(1) The ontological principle of non-contradiction: It is not possible for an object, at a given moment, to possess any feature and to contradict it at the same time, or briefly every being is not contradictory.

(2) An epistemological definition of truthfulness (one of several): The truth of judgments lies in their conformity with reality.

(3) The epistemological thesis of computationalism: Every cognitive act can be algorithmically described and implemented artificially with the use of computational machines, i. e. computers; or briefly: every cognition is a computation.
} 
mentioned concept of matter is assumed and specified in all natural sciences (which, after all, examine specific forms of matter); while the equally general concept of scientific law (precisely defined, inter alia, in the field of epistemology) permeates literally all fields of research in various variants. It is worth stressing that Immanuel Kant has opened the way for such an understanding of philosophy, noting that there are such universal ideas (as cause, space, or time), which cannot be derived from experience, but must still be used in the elaboration of empirical data ${ }^{4}$.

Getting closer to the main thread of the work, it is worth stressing that information is an important universal concept nowadays, which is located on the border of philosophy and specific sciences. From the philosophical point of view, this concept reveals a certain universal component of being, related to the Aristotelian form (it is claimed, for example, that information is the third constitutive element of the world, apart from matter and energy [15]). On the side of specific sciences, we have a number of specialist studies on specific forms of information, e.g. information contained in language utterances (this form is researched e.g. by linguistics and semiotics), or information processed using special types of machines (handled, among others, by computer science, electronics and automata theory).

2.2. It is no exaggeration to say that in the Western civilisation, initiated by the philosophical inquiry of the ancient Greeks and built up thanks to the successes of science, both philosophy and specific sciences have a significant impact on individual and social worldviews. About philosophy it is claimed, that the main function of it is to satisfy the needs of the human worldview.

This is how its role is defined, for example, by Władysław Tatarkiewicz, who writes in the first sentences of his three-volume "History of Philosophy" [27]:

"For as long as science has existed, efforts have been made to go beyond particular considerations, and include all that exists in one science; attempts have never been given up to build, along with specific sciences, one that would provide a worldview: this science has been and still is called philosophy".

While we remain within the circle of Polish philosophy, it must be said that such an attitude to philosophy and such a way of its practicing were the hallmarks of the LvovWarsaw School, close to Tatarkiewicz. It was repeatedly expressed by various representatives of the School, including its founder, Kazimierz Twardowski, and one of his most eminent disciples, Kazimierz Ajdukiewicz ${ }^{6}$. Paraphrasing the words of the first one,

\footnotetext{
${ }^{4}$ Let us add that the signaled distinction between philosophy and detailed sciences does not contradict the fact that contemporary philosophy, like all sciences, is divided into a number of specialist branches, in which individual general concepts/objects are studied in depth, although still very abstractly. Thus, metaphysics is interested in being and time, epistemology in knowledge and truth, and axiology in value systems that give meaning to human action (and each of the three disciplines is further divided into more specific sections).

${ }^{5}$ This quotation, as well as two subsequent ones (on this page and the next), are provided in author's translation of this article.

${ }^{6}$ For example, K. Ajdukiewicz [Ajdukiewicz 2003] describes metaphysics (together with epistemology, which supports it) as the way to gaining a final view of the world.
} 
uttered on the occasion of the 25th anniversary of the Polish Philosophical Society, we obtain the following declaration of the founder of the School [30]:

"The highest creative efforts of the greatest philosophers of all times served to form a well-founded view of the world and life. And to this day it is the most important side of any properly understood philosophical work."

2.3. Although from the above quotations and explanations there emerges a picture of worldview understood as something strongly intertwined with philosophy, both concepts should be distinguished. The most important difference between them is that the concept of the worldview (as opposed to philosophy) is psychological and, more broadly, social. In the first sense, it means a set of individual beliefs of a particular person in fundamental and vital issues (such as the nature of truth); in the second sense, it means a certain type of sociallygrounded individual worldview which, as a conceptual pattern, can shape the beliefs of particular people. In the latter sense, one speaks of a certain type of worldview, e.g. Christian, romantic, rationalistic, scientistic or mechanistic.

Socially well-established worldviews often play the role of a "philosophical leaven", a leaven that can be developed through the systematic work of scholars into mature concepts and theories. This is how Witold Marciszewski [18, p. 219] puts the case when he writes:

"We talk of worldview when we have in mind a view of the world which develops in a community in a rather spontaneous way, as a result of circumstances and demands of the time; philosophy, on the other hand, is a more systematic and theoretical development of these thoughts made by particular authors. As an example, we can look at the history of Christianity. The Christian worldview is already present in the gospels and letters of the apostles as a religious answer to the contemporary question about the meaning and purpose of life. Christian philosophy, on the other hand, does not appear even in its embryonic form until a whole century later, for example in Origen ...”.

2.4. Summarizing the above considerations, we can state that the relation between the worldview and philosophy is two-way and consists in mutual interactions. On the one hand, philosophical systems originate and develop thanks to spontaneously emerging worldviews, and on the other hand, philosophy provides concepts and theories that allow to satisfy people's worldview needs.

In accordance with point 2.1, these characteristics should be enhanced by the reference of interrelated areas of philosophy and worldview to particular sciences. This reference again takes the form of interaction, although this time it is about interaction at the "external" level, interaction with philosophy and with the worldview (or more precisely with their relations). At this new level, certain general (pre)philosophical concepts are gradually being defined, sometimes even formalised, and, secondly, certain philosophical insights (such as the Aristotelian concept of form) are permeating the sciences in a revitalising way.

The following remark by Kazimierz Twardowski [30] accurately captures this account: 
" ...some reciprocity is thus created: particular sciences draw on some ideas, notions and thesis from metaphysical systems, and metaphysical systems receive these ideas, notions and theses back from those sciences in a scientified form".

Within the framework of so outlined field of interaction it can be stated that in certain times certain sciences respond particularly well to current civilisation challenges and that they shape social views of the world in the strongest possible way (and thus: they foster the emergence of new types of philosophies). Nowadays, computer science is one of such sciences.

\section{Computer science and worldview}

But is computer science really the one among the particular sciences that has the strongest influence on the worldview attitudes (and more broadly: philosophical views) of contemporary man? In this chapter, I will briefly outline a few arguments for an possitive answer.

3.1. First of all, IT tools - both theoretical and practical - are used in a wide number of particular sciences, and their typical applications range from "simple" automation of calculations, through digital modelling and simulation of various phenomena, to attempts at creating new hypotheses by machines, which are not far from creativity. In short, the vast majority of specific disciplines successfully use some or other IT solutions.

The methodological fact that theoretical computer science is a formal science, whose formal objects, such as algorithms or data structures, can be interpreted in different problem areas, i.e. from the point of view of different sciences, harmonizes with the above argument. For philosophical reasons, two interpretations seem to be particularly important: a) cognitive - concerning human cognitive activities, and b) ontological - concerning the nature of being.

The first one owes the most to research on artificial intelligence [20], which provides effective methods and tools for modelling mental activities. For example, artificial neural networks model this kind of brain activity, which determines perception and learning. The second interpretation refers to more fundamental research (see [4], [9], [31]), and its core is the assumption that each being contains some informational content, which can be described - even roughly - by means of such notions as digital code, control code or algorithm. For example, if one takes Aristotle's hylemorphism as the right one, then the form that co-creates each being can be understood as a appropriately coded algorithm [28].

From the above, it is concluded that contemporary computer science has the status of a fundamental science, which determines research in other disciplines, including those that concern the mind and/or the essence of the reality.

3.2. Moving from methodological to social issues, it has to be stated that IT-based products - such as digital computers, tablets, smartphones, the Internet, social networking 
sites and millions of specialised applications - have a strong impact on people's social behaviour in terms of their lifestyles, how they communicate with others, their professional preferences and so on. As consequences of this vast range of these interactions sociologists more and more often define contemporary society as "information society" or "computerized society" [2], [11]. A philosophical aspect of this new cultural formation is the tendency to describe the world in terms of information.

In the social context, one more point is worth highlighting. Namely, computer science applications consist in an algorithmic solving of problems, while many such problems that are civilisational challenges for human beings. What is important, however, is that computer science not only helps to overcome certain difficulties, but also provides some theoretical results regarding the scope of possible algorithmicization. It turns out, for example, that not all problems - even if they are precisely defined - can be solved by means of algorithms. In other words, even a limited knowledge of the basics of computer science allows us to gain a socially important awareness of the limitations of certain methods of problem solving (perhaps even of any methods that are available to the human mind).

Summarizing the above arguments, contemporary computer science: a) is fundamental for other sciences, b) deals with information, c) provides a specific insight into the information content of being, d) allows to model the mind, and e) provides important social applications; and for all these reasons has a very strong impact on the awareness of the contemporary $\operatorname{man}^{7}$. We can even say more, that this impact goes beyond awareness itself, leading to an overall view of the world based on information technology concepts. We will further call this overall view 'informational worldview'.

\section{Informational worldview and related concepts}

The overall view of the world, which refers in a significant way to computer science, is called here the informational worldview (abbreviated as: IWV). Expanding slightly the characteristics given in the introduction, we can say that it is a certain type of prephilosophical views (in other words: protophilosophical one), which responds to the worldview needs of the contemporary man (living in an information society), concern the mind, the world and knowledge, and in the conceptual layer involve computer science concepts (such as code, algorithm or computability).

4.1. The concept outlined above (IWV) takes on a full meaning within a broader conceptual structure, which also includes: informational pre-awareness, informational awareness, and informational philosophy of the future, referred here to as informatism (see [18], [22]). The sequence given is not accidental, because it reflects, firstly, a certain chronology of events (how certain phenomena have been and will be occurring in social

\footnotetext{
${ }^{7}$ Here and later we talk about awareness in the social sense, which is a socially fixed conscious and reflectionstimulating familiarity with certain computer science concepts, computer techniques and their application.
} 
reality), and secondly, certain psychological dependencies (how the individual mind is developing more and more extensive and mature forms of informational awareness).

The first element of the proposed structure, i.e. informational pre-awareness, is the early form of the IWV, characteristic of the pre-computer age, expressed in the conviction that both information and various techniques of its processing are extremely important for a human being. At the root of this belief is a rational attitude (rationalism) typical for Western culture, which considers the primary obligation of man to seek knowledge, i.e. information that is maximally well justified. A practical expression of this attitude (and of the awareness intertwined with it) are breakthrough inventions for our civilization, such as: writing, numerical systems, logic, libraries, calculating devices, or printing. All of them are used to record, process and transfer various forms of information. For example, logic is used to process information truthfully and numerical systems allow digital coding of information.

The next element of the discussed structure, the informational awareness, could emerge from the "pre-aware" state as late as in the middle of the 20th century, with the spread of the information category in science and technology. The breakthrough event that triggered the information revolution was the invention of a universal information processing machine, i.e. a digital computer ${ }^{8}$. At present, two types of informational awareness should be distinguished: a) technological awareness - reflected in the ability to use various devices for data processing (including: computers), and at a deeper level, in the knowledge of theoretical basis for their operation, and b) prephilosophical awareness - going beyond technology, towards the philosophical belief that informational concepts apply not only to artifacts, but also to the human mind, social structures or biological reality.

The way to the informational worldview is opened by the awareness of the second type. It is thanks to it that such broad theses can be put forward as this, that the deepest basis of all kinds of phenomena are some computations (implemented on a specific type of code, e.g. digital), or that the human mind is in the elementary mathematical sense reducible to a Turing machine. Such theses are undoubtedly present in contemporary philosophy, they also have a powerful mathematical and computer science base, however, they do not yet form a comprehensive coherent system which could be described as a mature informational philosophy. Such a philosophy, which we could call informatism (forming the term and the concept by analogy to mechanicism) should be considered a far-reaching project, which currently has the status of an expanded vision of the world (see [18], [13], [8]).

4.2. The theoretical basis of the informational worldview is constituted by computer science concepts, which in their source form, before their wider interpretation, concern certain computational techniques.

The following concepts ${ }^{9}$ are particularly important for the IVW:

\footnotetext{
8 In addition to the invention of computers, other developments in specific sciences, such as new telecommunications technologies (telegraph, telephone, telecommunications networks) and discoveries in biology (genes, inheritance theory, DNA code), have had a major impact on the development of a new type of awareness.

${ }_{9}^{9}$ These concepts will be defined in a descriptive, informal way, adapted to the philosophical style of the text. Their formal implications can be found in any manual of the theory of computation (e.g. [9]).
} 
a) information - understood in the field of computer science as data, possible to process by a specific type of the automaton (e.g. digital computer);

b) code - a precise method of data recording, matched to the capabilities of the machine processing the data (e.g. digital or analog code);

c) computing - processing of appropriately encoded data, according to the rules that are 'understandable' to a certain automaton;

d) algorithm - an abstract scheme of computations necessary to solve a certain problem;

e) model of computation - a formal description of principles and methods of data processing of a specific type (e.g. digital computations comply with the principle of data discreetness and the principle of a finite number of steps of computation);

f) universal Turing machine - an abstract machine whose structure and principles of operation determine (mathematically) the digital model of computation;

g) computational complexity - understood as a type of function that links the size of the problem (the measure of the amount of input data) with the number of elementary computations that are necessary to solve the problem;

h) computability and uncomputability - the property of a problem which consists in the fact that in a given model of computation there exists an effective algorithm for solving this problem (a computable problem) or there is no such an effective algorithm (an uncomputable problem);

i) computational power of the model - the range of problems that can be resolved in a given model of computation.

A worldview interpretation of the presented concepts (as well as of related or derived from them) consists in their relation to man and the world. Therefore, it consists in giving them new meanings, which, however, have a very strong connection with the primary meanings (e.g. when interpreting an data processing system as a partial model of the mind, we refer to the purely computer-based properties of this system).

These new meanings constitute a kind of an informational picture of the world (outlook on the world), and going further, not only a picture, but a set of justified beliefs about its elements (worldview) ${ }^{10}$. The difference indicated in the last sentence is extremely important because it shows that simply perceiving the world in terms of information technology does

10 In two other texts, I discuss in detail the difference between the worldview and the outlook on the world. See [23], [24]. 
not automatically lead to a worldview. For the latter to exist, questions are needed which, on the one hand, are a result of reflection on the world in terms of computer science and, on the other hand, lead to conclusions that shape a particular worldview (and not only an outlook). An example of such a view is the optimistic conviction that every problem that cannot be solved at a given stage of human cognition can become, as a result of the development of computational techniques and the concepts behind them, solvable (computable). Such a position is presented, for example, by Witold Marciszewski [16], who indicated as its precursors David Hilbert and Kurt Gödel.

Bearing in mind the indicated difference between the outlook and worldview, we can provide several theses characteristic for the informational outlook on the world - theses that are the starting point for further worldview decisions. We will write them down in a form as brief as possible, even metaphorical, indicating the areas in which they are most intensively used and developed:

T1: world as a result of computations (thesis accepted by some physicists, originating from G.W. Leibniz; see [16]);

T2: mind as an information processing system (which is taken as a starting point by, among others, cognitive scientists; see [19]);

T3: cognition as a computation (which is a concretisation of the thesis T3; see [19])

T4: organism as a kind of automaton and its developmental pattern ${ }^{11}$ as a code (which corresponds to the practice of geneticists dealing with, inter alia, the DNA code) ${ }^{12}$.

4.3. Because of the further part of this work, I will briefly develop the contents of the T2 thesis (the mind as an information processing system), revealing interpretations of the above mentioned IT concepts that are important for it. These interpretations become sensible in the context of the mind-modelling strategy using computational systems (such as rule-based or connectionist systems) that is typical for IWV [21].

Within this strategy, it is assumed that the content of the mind (what the mind processes) is a kind of code which has numerical representation at the elementary mathematical level of description (e.g. digital codes are represented by natural numbers and analogue codes by real numbers). It is also assumed that the activity of the mind is some sort of processing of data - a computing that falls under a specific model of computation (e.g. digital). In the context of this model, it makes sense to formulate a hypothesis that the limitations of the

\footnotetext{
${ }^{11}$ When we use the term "developmental pattern", we mean the fact that each organism (belonging to a certain species) has its own developmental cycle (e.g. from the embryo to a mature individual), which is physically coded in a specific way inside the organism (e.g. in the form of a DNA code).

${ }^{12}$ Note that the above formulations define a certain way of seeing the world: we perceive something as ... e.g. the mind as a system that processes information. At the same time, this way of viewing causes that a certain computer science concept, standing on the right side of the word "as", acquires a new, non-technological meaning. For example, computation is interpreted as cognition (T4).
} 
model, i.e. its inherent uncomputable problems, set the limits of human cognition; in other words, that the computational power of the model matches the cognitive power of the mind.

To sum up, it must be said that by adopting thesis no. 2, we obtain a general informational view (image) of the mind, on the basis of which we can ask questions that lead to some kind of worldview. Among them are the following two: $\left(\mathrm{p}_{1}\right)$ what kind of code (e.g. digital, analogue, or perhaps another) describes the content of the mind, $\left(\mathrm{p}_{2}\right)$ is the essence of the mind algorithmic, and if so, does it affect the cognitive limitations of the mind?

\section{Philosophical potential of the concept of the Turing machine}

In the last chapter of this paper I will elaborate further on the thesis that compares the mind to an information processing system, but this time I will refer specifically to Turing's model of computation. I will consider the following issue: "In what sense can the human mind be compared to the Turing machine?" or shorter, "What does it mean that the mind is a Turing machine?" ${ }^{13}$. The presented analyses will be a partial justification of the thesis that the informational worldview paves the way for the informational philosophy, i.e. it allows to pose and analyze initially important philosophical issues.

5.1. Historically, the concept of the Turing machine that we are interested in here was introduced to the science by the English mathematician, Alan Turing [29], who used it to define precisely (mathematically) what should be understood by algorithm, i.e. the procedure of mechanical processing of symbolic data into symbolic results ${ }^{14}$. Although Turing's idea is called a machine, i.e. something physical, in fact it combines two meanings: hardware (physical) and software (logical).

According to the first meaning the Turing machine is a physical device equipped with a potentially infinite tape divided into cells, a head for reading/writing symbolic data (encoded in a specific alphabet) and a physically executed (e.g. mechanically or electronically) instruction table controlling the movements of the head. This device operates on the basis of the program contained in the instruction table, each instruction having the form of a conditional statement: if (the current state of the machine is $x$ and the head reads the symbol s), then (change the state to $y$, change the symbol to $p$ and move the head one cell to the right or left). Following the instructions, the machine changes the content of the tape until it stops in the final state and leaves a sequence of symbols on the tape which is the

\footnotetext{
${ }^{13}$ This leads to further, more advanced questions, which we will no longer address here. For example, "Does the mind have greater computational power than the universal Turing machine?" or "Is the mind a Turing machine with an oracle?". See [16], [17].

${ }^{14}$ Before 1936, the concept of algorithm was used intuitively (though effectively), which made it impossible to formally analyse it, which could lead, for example, to identifying the limits of the algorithmic method.
} 
encoded result of the task assigned to it. The most important thing, however, is that the Turing machine, understood in hardware terms, can actually do all this, similarly to actual digital computers [9].

Since the key element of the mechanism described is the instruction table or program, the Turing machine is more often located in the area of programming theory, and this leads us to the second of the meanings mentioned above. In the latter sense, Turing's construction is a theoretical idea which shows what mechanical data processing is all about, i.e. what algorithmic operation consists in. According to this idea, data must be unambiguously encoded and then undergo strictly defined transformations, described one after the other, without any gaps in the machine program. In such an approach the physical construction of the machine does not matter much; it is important that the operation of the machine is somehow correlated with its program (and Turing simply provided some extremely simple and rather theoretical scheme of such correlation).

At this point, we need to clarify one more point, which is crucial from the point of view of an abstract theory of computation. Alan Turing actually developed two types of machines. Firstly, they were specific machines - equipped with specific programs for performing specific tasks (e.g. adding numbers). Secondly, these were universal machines equipped with special programs for simulating the operation of any specific machines [29]. And what is very important: although the machines of the second type can be defined or designed in different ways (it depends on the number of their elementary internal states), because they are all identical in terms of simulation capabilities, they are replaced (in the mathematical sphere of abstraction) by a collective concept of the one universal Turing machine (in abbreviation: UTM).

If one thinks about the UTM machine as a device that actually works, it operates in the following way. On its tape a encoded description of a specific M machine (strictly speaking: the program that defines it) and the input data of the M machine are entered. Then the UTM machine reads alternately: once the input data of the $\mathrm{M}$ machine, once its instruction table (this is what controls its universal program) and depending on the current instructions it writes on the tape the appropriate symbols. As these are the same symbols that would appear on the tape of the automat M, about the UTM machine it has to be stated that it simulates the operation of the automaton $\mathrm{M}$, the program of which was supplied to it. And what is extremely important: it can imitate any specific machine in the same way.

5.2. But why are the above concepts so important for modern computer science, especially those branches that focus on digital computer applications? The answer may seem surprising, but from a mathematical point of view it is true. The Turing machines are equivalent to digital computers ${ }^{15}[9]$.

\footnotetext{
${ }^{15}$ More specifically, equivalence occurs between digital computers and Turing machines, with finite tapes (finite length tapes). The introduction of infinite tape makes the Turing machine (in particular the universal Turing machine) an ideal machine; a mathematical object that has to be understood as a model of a digital computer. These issues are further elaborated.
} 
From the programming point of view, this fact can be expressed as follows: every program for a digital machine, regardless of its complexity and hardware requirements as to the speed of the processor, can be properly coded and executed by a device as simple as described by Alan Turing. In other words, the digital computers and the Turing machines are equivalent to each other in terms of the range of tasks that can be carried out, and this is because every program for a digital machine can be translated into a set of instructions for a Turing machine. However, with a fairly obvious reservation: although the scope of the problems to be solved is the same in both cases, the pace of implementation of the programmes (as well as their clearness) must be different in each case (and the progress in digital data processing technologies still serves the purpose of increasing this pace).

Let us return, however, to the Turing distinction between specialized and universal machines. In its light the above thesis about equivalency of Turing machines and digital computers is "splitting". Firstly, a specific TM machine is equivalent to a computer running a specific program (e.g. a program for summing up numbers); secondly, the universal UTM machine is equivalent to a computer, not equipped with specialized software, but prepared to run various possible programs.

To sum up, the universal Turing machine (UTM) is an abstract model of operation of programmable digital computers, what should be understood as a claim that each program for a digital machine can be coded in a form feasible for a specific TM machine, and thus for a UTM machine as well ${ }^{16}$.

5.3. Having explained the computer science concept of the Turing machine, we can proceed to an interpretation of the thesis according to which the mind is in a crucial sense similar to such a machine. In view of the equivalence between Turing machines and digital computers discussed above, this thesis, expressed in less technical terms, shows a similarity of mind to a digital computer ${ }^{17}$.

But what does this mean specifically? And how do the components of a computer (e.g. a digital one) relate to the structure of the mind?

The overall correspondences seem obvious. Firstly, the biological basis of the mind, means the brain (which is also a mental subsystem), has its counterpart on the side of the physical component of the computer (hardware). Secondly, the informational content of the mind that is a kind of mental software forces the brain to operate in one way or another, finds its computer counterpart on the side of computer software.

And having translated these relations into the language of Turing machines, the following would have to be said. The biological part of the mind, that is, the brain, corresponds to the physical equipment of the Turing machine (tape, head, etc.), while the

\footnotetext{
${ }^{16}$ It should be noted that the opposite is also true: any program that a universal Turing machine can execute using the finite part of its tape is also feasible for a certain digital machine. On the other hand, a program that is not executable for UTM is also not executable for any digital computer [9].

${ }^{17}$ Generally speaking, the thesis about the similarity of the mind to the computer is expressed in the fact that: 1) the mind, like a computer, processes the information it receives (visual, sound, etc.), and 2) just as the computer controls (if necessary) the physical activities of the device it is linked to, i.e. the body. See [10], [12].
} 
mental software of the brain corresponds to the instruction table of the machine. It is not claimed that the mind is a Turing machine in the literal sense (means that actually exist a brain head or a set of mental instructions that control this head). It is said ONLY that there are the above correspondences. But also SO MUCH that the computational power of the human mind, i.e. the range of problems it can solve, is the same as that of the Turing machines (collectively represented by the UTM universal machine).

The last sentence is very important because it reveals the essential sense of the procedure of bringing digital computers and human minds down to the level of an extremely simple machine, controlled by extremely simple instructions. The point is to simplify the analysis. It turns out that by analyzing such a simple construction ${ }^{18}$ as a Turing machine it is relatively easy to determine the limits of the mind's possibilities compared to a digital computer. In particular, limitative theorems known from the theory of computation [6] concerning the existence of uncomputable problems can be used to determine these limits. Let us recall that one of them is the halting problem of Turing machines, and the other is the problem of resolvability of diophantic equations.

5.4. The conclusion of point 5.3, expressed in one sentence, is as follows: "When comparing the mind to the Turing machine, one refers to the hypothesis that the cognitive power of the mind, so the range of problems it can solve, is identical to the computing power of digital computers, which in terms of this power are equivalent to the Turing machines".

However, despite such a precisely drafted conclusion, the key question remains. How should we treat the mind that is concerned by this hypothesis? Due to the ambiguity of the concept of the Turing machine, as well as the characteristics of the mind, three possibilities arise [18].

Firstly, the individual mind can be treated as a time variable object, which in subsequent periods $\mathrm{T}$ has a different information content, and thus exhibits different possibilities. This is what everyday observation leads to - after all, we ourselves, undoubted mind holders, are constantly developing, learning, gaining new experiences and, as a result, the content of our minds, if not improving, is at least changing. Because of these changes the changes that occur with the elapse of time $\mathrm{T}$ - we propose to call the variable mind a "Tmind". Expressing its essence in computer terms, we could say that the T-mind is a computer that has access to different programs at different times; the open question is whether these programs are provided from outside or whether the mind creates them and activates them itself (importantly, that at different times the mind has different sets of programs at its disposal).

Secondly, however, the mind can be understood as a certain unchangeable whole, which seems to be only changing, but actually contains a full, once and for all defined, algorithm of action. This algorithm is so complex (or so: its code is such a huge number) that it is impossible to unravel all its complexities and to determine with certainty how this algorithm would work in all circumstances. In fact, however, the algorithmic scheme is

\footnotetext{
${ }^{18}$ The simplicity of the construction does not mean that the reasoning that proves the computational limitations of the Turing machines is simple.
} 
strictly defined and the mind is strictly deterministic. (It seems that this is how Leibniz perceived the mind, describing it as a closed, once and for all defined, monad [14]). Therefore, it would be some unchangeable, static superstructure, controlling the organism in a total way - hence its proposed name: "S-mind"; with the letter S, which is to emphasize the assumed the assumed static nature of the mind. Returning to computer stylistics, one would have to say that the S-mind resembles a supercomputer equipped with extremely sophisticated software, covering billions of ready-made procedures intended for all possible situations (possibly: if some of these procedures are not ready directly, then the "mental software" can generate them reliably using certain well-defined schemes of selfimprovement, i.e. learning).

Thus, we obtain two extremely different interpretations of the mental domain: on the one hand, a variable and probably undeterministic T-mind, and on the other hand, a constant and probably deterministic S-mind. Somewhere between them, or rather within them, there is a third possibility, namely the mind reduced to the minimum of algorithms that allow it to complete any other algorithmic procedure. Let's call this possibility a "minimum mind", which can be shortened to a "M-mind". The question is, of course, whether the last concept has any sensible meaning, and therefore whether psychologists are considering any equivalent of the M-mind. The answer seems to be immediate. The mental minimum would be the same as a certain innate knowledge, thanks to which all people develop in a similar way, reason similarly and act in a similar way, doing different things automatically.

The careful reader of the text probably noticed the similarity between the M-mind that contains innate knowledge, and the universal Turing machine (UTM). Let us remind that UTM is able to simulate each specific Turing machine, thanks to a program that is used to read and execute codes of all other machines (codes treated as input data of UTM). Similarly, the minimal M-mind is able to interpret and execute appropriately every algorithmic procedure provided to it (independently of where this procedure comes from).

And so we returned to the concept of the Turing machine, which is the thematic axis of this chapter. With this concept in mind, let us explain synthetically what a thesis equating the mind with the Turing machine means in the light of three different interpretations of the mind (hypothetical interpretations).

Let us list:

(1) the variable $\mathbf{T}$-mind has to be compared to a series of specific Turing machines (partial machines if one considers all the problems that can be solved by Turing machines);

(2) the invariable S-mind can be compared to a specific Turing super-machine (a machine whose program allows to solve all the problems available to a given mind; obviously, that this program must be extremely complex and large).

(3) the minimal M-mind can be compared to the universal Turing machine UTM (i.e. a machine capable of simulating each specific machine, provided that the UTM receives its program). 
This gave us three different answers to the question of what it means that the mind resembles a digital computer, that is, by bringing the issue down to the theory of computation, the Turing machine. Within each answer, further philosophical questions about human cognitive abilities can be asked and resolved. Surely they include the following: "Is the human mind subject to the same cognitive limitations as the Turing machines?", "Does the human mind perform any hypercomputations, and if so, can they be effectively modeled with the use of Turing machines?". However, these are the topics for the new article.

\section{References}

[1] Ajdukiewicz K., Problems and theories of philosophy (in Polish: Zagadnienia i kierunki filozofii, Wydawnictwo Antyk - Fundacja Aletheia, Kęty-Warszawa, 2003).

[2] Bell D., The Coming of the Post-Industrial Society, Peguin Books, Harmondsworth, 1973.

[3] Bolter J.D., Turing's Man. Western Culture in the Computer Age, The University of North Carolina Press, Chapel Hill, 1984.

[4] Burgin M., Dodig-Crnkovic G., Typologies of Computation and Computational Models, 2013, arXiv:1312.2447 [cs].

[5] Cafe Aleph (http://blog.marciszewski.eu/), an academic discussion blog of W. Marciszewski and P. Stacewicz.

[6] Chaitin G., The Limits of Mathematics, Springer-Verlag, Singapore, 1998.

[7] Dodig-Crnkovic G., Giovagnoli R., Computing nature: Turing centenary perspective, Heidelberg, New York 2013.

[8] Floridi L., The Philosophy of Computing and Information, Blackwell Publishing, Oxford, 2004.

[9] Harel D, Algorithmics: The Spirit of Computing, MA: Addison-Wesley, 1987.

[10] Hetmański M., Mind and Machines. The critique of computational theory of mind (in Polish: Umyst a maszyny. Krytyka obliczeniowej teorii umystu, Wydawnictwo UMCS, Lublin, 2000)

[11] Ito Y., Birth of Joho Shakai and Johoka Concepts and Their Diffusion Outside Japan, Keio Communication Review, 13, 1991, 3-12.

[12] Johnson-Laird P.N., The computer and the mind: an introduction to cognitive science, Harvard University Press, Cambridge, 1989.

[13] Jos De Mul, The informatization of the worldview, Information, Communication \& Society, 2:1, 1999, 69-94.

[14] Leibniz G. W., The Monadology, translated by R. Latta, Clarendon Press, Oxford, 1898. 
[15] Lubański M., Information - System (in Polish: Informacja - System, [w:] Heller M., Lubański M., Ślaga S.W. (red.), Zagadnienia filozoficzne współczesnej nauki, Wydawnictwo Akademii Teologii Katolickiej, Warszawa, 1997)

[16] Marciszewski W., Rationalistic cognitive optimism in Gödel's vision of the dynamics of knowledge, (in Polish: Racjonalistyczny optymizm poznawczy w Gödlowskiej wizji dynamiki wiedzy, [w:] Ziemińska R. (red.) Przewodnik po epistemologii, Kraków, 2013)

[17] Marciszewski W., The Gödelian Speed-up and Other Strategies to Address Decidability and Tractability, Studies in Logic, Grammar and Rhetoric, 22, 2006, 9-29.

[18] Marciszewski W., Stacewicz P., Mind - Computer - World. About the riddle of the mind from an informational point of view (in Polish: Umyst - Komputer - Świat. O zagadce umystu z informatycznego punktu widzenia, Akademicka Oficyna Wydawnicza EXIT, Warszawa, 2011).

[19] Miłkowski M., Explaining the Computational Mind, MIT Press, 2013.

[20] Russell S., Norvig P., Artificial intelligence: A modern approach, Prentice-Hall, Englewood Cliffs, NJ, 1994.

[21] Stacewicz P., Mind and Models of Learning Machines. Modern Computer Science Research from the Philosopher's Perspective (in Polish: Umyst a modele maszyn uczacych się. Wspótczesne badania informatyczne w oczach filozofia, Wydawnictwo EXIT, Warszawa 2010).

[22] Stacewicz P., Informational Worldview. Scientific Foundations and Philosophical Perspectives, Studies in Logic, Grammar and Rhetoric, 47(60), 2016, 35-47.

[23] Stacewicz P. (red.), Computer Science and Philosophy. From Computer Science and its Applications to the Informational Worldview, (in Polish: Informatyka a filozofia. Od informatyki i jej zastosowań do światopoglądu informatycznego, Oficyna Wydawnicza Politechniki Warszawskiej, Warszawa, 2015).

[24] Stacewicz P.. Informational Worldview. An Optimistic or Pessimistic Vision of the World (in Polish: Światopogląd informatyczny. Optymistyczna czy pesymistyczna wizja świata, [w:] Spory o wartości: aspekty filozoficzne i administracyjno-prawne , Zubelewicz J. (red.), Oficyna Wydawnicza Politechniki Warszawskiej, Warszawa, 2015, 73-88).

[25] Stacewicz P., The Informational Conceptual Apparatus and Worldview, preparaed for printing.

[26] Stępień A., Introduction to Philosophy (in Polish: Wstęp do filozofii, Wydawnictwo Towarzystwa Naukowego KUL, Lublin, 1995).

[27] Tatarkiewicz W., History of Philosophy (in Polish: Historia filozofii, t. 1-3, PWN, Warszawa, 1990).

[28] Turek K., Philosophical Aspects of the Concept of Information (in Polish: Filozoficzne aspekty pojęcia informacji, Zagadnienia Filozoficzne w Nauce, I, 1978, 32-41).

[29] Turing A. M., On Computable Numbers, with an Application to the Entscheidungsproblem, Proc. Lond. Math. Soc., 42, 1936, 230-265. 
[30] Twardowski K., Selected Philosophical Papers (in Polish: Wybrane pisma filozoficzne, PWN, Warszawa, 1965).

[31] Wirth N., Algorithms + Data Structures = Programs, Prentice Hall, Englewood Cliffs, 1976.

Received 26.06.2018, Accepted 18.01.2019 